$12-29-2017$

\title{
Improving wayfinding and signage systems of the Ragunan Zoo as a way to enhance visitors' quality time
}

\author{
Yulia Nurliani Lukito \\ Department of Architecture, Faculty of Engineering, Universitas Indonesia, yulia.lukito@gmail.com \\ Enira Arvanda \\ Department of Architecture, Faculty of Engineering, Universitas Indonesia
}

Follow this and additional works at: https://scholarhub.ui.ac.id/ajce

Part of the Social and Behavioral Sciences Commons

\section{Recommended Citation}

Lukito, Yulia Nurliani and Arvanda, Enira (2017). Improving wayfinding and signage systems of the Ragunan Zoo as a way to enhance visitors' quality time. ASEAN Journal of Community Engagement, 1(2). Available at: https://doi.org/10.7454/ajce.v1i2.76

Creative Commons License

\section{(c) (i) ()}

This work is licensed under a Creative Commons Attribution-Share Alike 4.0 License.

This Research Article is brought to you for free and open access by the Universitas Indonesia at ASEAN Journal of Community Engagement. It has been accepted for inclusion in ASEAN Journal of Community Engagement. 


\title{
Improving Wayfinding and Signage Systems of the Ragunan Zoo as a Way to Enhance Visitors' Quality Time
}

\author{
Yulia Nurliani Lukitoa*, Enira Arvandaa \\ ${ }^{a}$ Department of Architecture, Faculty of Engineering, Universitas Indonesia
}

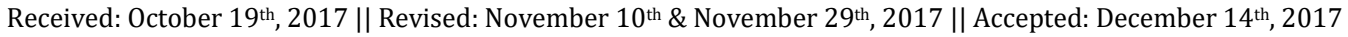

\begin{abstract}
Ragunan zoo is the biggest zoo in Jakarta and one of the most favorite recreation areas during holidays. Unfortunately, the existing signage in the zoo does not provide simple wayfinding and good signage systems that resulted in the confusion of visitors in exploring the zoo. Besides recreation, the zoo also functions as educational and conservational areas. Confusing wayfinding and signage influence visitors' enjoyment during their visit and their motivation to fulfill the education and conservation goals. This paper analyzes existing wayfinding and signage systems at the Ragunan Zoo and proposes a more comprehensive system by using some basic principles of wayfinding and signage design. We collaborated with the Ragunan Zoo management in developing a community park and conducted a field research between February and October 2017. The study includes analyzing visitor's movement patterns and mapping the location of animals and facilities as well as visitors' behavior in relation to wayfinding and connection to the environment. The method of this study is qualitative, such as analyzing patterns of movement and connecting to environment. Field research and observation are also parts of the approach used to map areas in the zoo, so that we understand the needs of both visitors and the management. The paper argues that by applying basic principles of wayfinding such as structuring space and information as well as good signage designs such as visual representations for the Ragunan Zoo, visitors will have more time to enjoy their visit and be involved in education and conservation activities.
\end{abstract}

Keywords: zoo; wayfinding; signage design; Ragunan; zoo design

\section{Introduction}

Taman Margasatwa Ragunan or Ragunan Zoo is a 147-hectares park located at Pasar Minggu, South Jakarta, and home for more than 2,100 animals and 50,000 trees. This zoo is a miniature of tropical forest for having great biological diversity and a good value of animal and tree conservation. The Ragunan Zoo was a development of the former Cikini Zoo found in the nineteenth century and inaugurate by the governor of capital Jakarta Ali Sadikin on June, 22nd 1966 in its new location. Nowadays, the Zoo is one of the favorite attractions during holidays for people living in Jakarta and nearby cities.

The Ragunan Zoo records a significant increase of visitor numbers during the long holidays. The number of visitors for instance reached almost 136,000 during the 2017 Idul Fitri holiday, while during regular months the number of zoo visitors is around 3,000 people on weekdays and 40,000 on weekends (the Jakarta Post, June $30^{\text {th }}, 2017$ ). Visitors can experience lots of entertainment in the zoo and with well-maintained environment the zoo is very comfortable to explore, especially for families with children. The zoo opens from 6 AM to 6 PM except on Monday when the Zoo is closed for public. Besides for family, in early morning some visitors come to the Zoo to do sport activities such as jogging and cycling, and during weekdays the Zoo is very often used as a field trip destination for school children.

Despite such tremendous upkeep, visitors might experience getting lost and confusion in this big environment, especially with inefficient signage and wayfinding systems. Orientation to the zoo's plan seems to be a problem for many visitors of the Ragunan Zoo. Some visitors miss animal exhibits because they cannot find the location of those exhibits or do not use labels and signage to their fullest potential - an indication

\footnotetext{
*Correspondence Author: yulia.lukito@gmail.com
} 
Yulia Nurliani Lukito, Enira Arvanda | ASEAN Journal of Community Engagement | Volume 1, Number 2, 2017

that zoo management have not used signage effectively. It is not easy for visitors who get separated from their families or friends to locate them or for their families and friends to find them - an indication of confusing signage and lack of landmark or identity for some areas.

Before visitors get interested in education or conservation, the two things they usually are interested in are animals and leisure. Live animals and exciting experiences with nature in the zoo offer visitors not only recreation but also interpretation of exhibits and environmental education. Zoo interpretation then usually begins with the concrete and spontaneous experiences the zoo visitors have with the animals. In addition, navigating through an environment of free vision should generate an exciting experience of learning and discovery. Psychologist Mihaly Csikszentmihalyi (1990) mentions this condition as flow or a psychological state of most favorable experience and asserts the importance of nurturing a state of flow so that visitors can have learning opportunities surrounding them. Designers can direct visitors to learn from the environment through a good design that inspires wonder and gives clarity, including through designing signage and information boards. From the perspective of visitors, good signage and clear wayfinding system prevent confusion in exploring the zoo and make visitors have more time, and thus, more learning opportunities. From the perspective of the zoo management, good signage and clear wayfinding system supports the management in organizing their collection. Good signage and simple wayfinding system will significantly reduce 'lost incident' or losing a group member during a visit in the zoo and increase visitors' confidence in finding a place of interest. In this way, the improvement of wayfinding and signage systems will change the condition in the zoo significantly and help visitors to have better experience in the zoo.

The terms wayfinding and signage are often used in public space to direct people and give information on the environment and the exhibits. The main objective of a signage program is to help people find their way through an environment whereas effective wayfinding system often involve more than just signage alone. Well-designed pathways and visual cues, such as landmarks and maps will improve wayfinding. The main purpose in wayfinding design is to enable people to create a mental map of an environment and comfortably navigate from one place to another. Wayfinding is an active process, involving mental engagement and attention to the environment a person is trying to navigate. Thus, a sign program most likely cannot help people navigating the site that contains confusing pathways.

It is the aim of this paper to discuss wayfinding and signage systems in the Ragunan Zoo and to suggest an effective signage design by using knowledge and theory in designing wayfinding and signage for the zoo. The first part of this article explains the importance of designing wayfinding and signage system in the Ragunan Zoo based on the observation in the field. The second part of this article elaborates the new design for wayfinding and signage systems in the Ragunan Zoo that implements theory and design knowledge. The main argument in this paper is that applying design knowledge in creating wayfinding and signage systems can contribute to the increasing ability of visitors to learn more from the exhibits and use their time effectively in the zoo. In the end, a good signage design will create landmark and unique identity of the zoo.

\section{Theoretical Background}

In the zoo, there are some activities other than animal exhibits that also attract visitors such as walking, eating, and using playground. The layout of the exhibits determines visitor traffic patterns and visitors spend decreasing times at each exhibit 
(Taylor, 1986). This means visitors most likely spend more time at the first exhibits before begin losing interest in the next exhibits. As a result, the environment also influences the group's attention to the exhibits since visitors may have decided what they want to see at the beginning of their visit (Benton, 1979). Hence, the way visitors understand the environment and how they grasp information from signage are very important.

Wayfinding is the mental processes of orientation in space and those processes must begin with the physical experience of space. Christian Norberg-Schulz (1971) states that any functional action has particular spatial implications and one must understand spatial relations and unify them in a space concept in order to carry out our intentions. It means that space and orientation create the basis of all meaningful relationships we make with our environment and signage should help people to understand spatial relations.

There are some important aspects that influence the way one experience space according to Norberg-Schulz (1971). First, establishing one's relative position within a system of spatial relationships is essential. Establishing a system for orientation becomes a determining aspect in our ability to connect to the environment. The second is the aspect of recognition that includes the perception of identifiable features, both topographical and human built. Structuring spaces around us is a very intuitive motivation to provide some elements for recognition. A sense of direction is connected to the perception of known landmarks and landscape as we move to different places (Gibson, 2009) while boundaries of regions provide a spatial framework for positioning ourselves (Golledge 1995). Kozlowski and Bryant (1977) assert that a sense of direction is related to the accuracy of cognitive map - a mental representation that preserves survey knowledge of a familiar environment. Survey knowledge in the cognitive map includes metric and relational information about paths, landmarks distances, directions, and the configuration of objects that may be simultaneously represented as if seen from a bird's-eye view (Hart and Moore 1973) while architectural features such as signs also play a role in the cognitive map. Moreover, people are capable of various methods of wayfinding depending on the information available to them and considerations of efficiency and aesthetics (Cornell and Heth, 2000). In short, wayfinding is an active process that includes not only how people connect themselves to the environment, but also both cognitive maps and architectural features.

Designing for public buildings, parks or urban areas needs a research and planning to establish good design and to have approaches sensitive to users. Detailed site survey and mapping, for instance, are a means to show what strategies and sign messages might be employed to get overall visual impact. Different strategies may be used during the initial stages of planning to gain a deeper understanding of these issues. Analyzing user-behavior can provide valuable information on traffic patterns, while survey studies often reveal characteristics needed in designing space and accommodating user preferences. In addition, systematic navigation may affect how users are likely to stop to determine where to go as well as provide users with the suitable means of reassurance (Arthur \& Passini, 1992).

The aspect of visual representation is also critical for wayfinding and signage design. It is important to incorporate a design that support an effective interaction between user and communication content. Therefore, chosen representation codes such as maps and pictograms as well as the structuring of information or typographic design must fall within the range of experiences and knowledge of users, or involve a minimum amount 
Yulia Nurliani Lukito, Enira Arvanda | ASEAN Journal of Community Engagement | Volume 1, Number 2, 2017

of learning. In selecting metaphors or analogies for signage, however, we must always account for unintended interpretations before they become effective.

Hierarchical mapping is another way of familiarizing users with spaces, through provisions which permit the relationships among parts to become explicit (Correa de Jesus, 1994). Knowing the degree of importance and the relative position of individual spatial components to the whole can greatly reduce ambiguities and simplify decisionmaking when users navigate. Furthermore, if settings are complex, the process of "diagramming" routes and destinations must rely less on user memorization and more on communication reassurances and a degree of redundancy. This process can be supported by sign messages which encourage users to locate main destination zones and then be led to the more specific spaces which might be physically or functionally related to them. It also is important to consider a reverse flow of communication to help users determine their relative position in a setting and return to their point of departure with ease.

Also, factors such as the design language itself determine the extent to which users will be engaged in decoding messages presented to them. The communication process between design and user does not begin until the user turns his or her mind to the message. Combined with the user's experience, interests, or needs, the design language then becomes a major factor in the success or failure of communication.

Signage and way finding are most usually expressed in united sign programs that informationally and visually interweave a site and a collection of related sites (Calori \& Vanden-Eynden, 2015). Well-designed signage programs help to visually unify a site, while signage can also function to establish a unique identity and sense of place. Moreover, wayfinding and signage programs can also communicate other kinds of information, such as warning and operational information.

Signage has a variety of forms, presenting various methods of regulating the location, size, and other features associated with on premise signs. Such sign codes are often developed at the local level and may rely upon aesthetic preferences. Visitors want concrete information from the display, but the signage or labels are often focused on more abstract concepts. Because visitors spend longer periods viewing exhibits at the beginning of their visit (Taylor, 1986), signage should work very well at the beginning of the visit so that visitors grasp the information they need.

\section{Methods}

Designing signage and wayfinding for parks, zoo or public spaces needs a proper research and planning to have good design with approaches sensitive to users. Before designing signage, we conducted a site survey and did a mapping of visitors' mobility in the Ragunan Zoo. Analyzing user-behavior provides valuable information on traffic patterns while survey studies reveal characteristics needed in accommodating user preferences. Since systematic navigation may affect how users are likely to stop to determine where to go, it is our intention to find out what areas or crossings need signage to provide users with the suitable means of reassurance. Between February and August 2017, we visited the Ragunan Zoo in different times such as during the weekend and the weekdays, in the morning and in the afternoon.

We use both qualitative and quantitative approaches in analyzing the information from our visit in the Zoo and tries to create hierarchical signage system and effective wayfinding. Analyzing user-behavior is conducted to get valuable information on traffic patterns and user preferences, as well as systematic navigation. At the design stage, we divided the information on the signage based on visitors' need and classified the 
information into exhibits, facilities, identity of certain areas to create unique and memorable wayfinding.

This project is related to community-based program because community members are included and benefited from the improvement of wayfinding and signage in the Ragunan Zoo. For example, the support of the management office to accommodate visitors' need while in the zoo means that there is a good engagement with the community. Furthermore, according to a community-based perspective, the participation of community members should be central, to address successfully local concerns (Minkler \& Wallerstein, 2003). In the case of this wayfinding and signage project, the mapping of visitor's movement and interest while in the zoo is the base for the wayfinding and signage design. Through the participation of visitors to determine which collections and paths in the zoo are crucial for their visit, the proposed wayfinding and signage system will promote independency of visitors in exploring the zoo. The significance of this kind of participation, therefore, relates this project to the idea of community engagement that the zoo management is not the only party who should decide how visitors explore the zoo. Because visitors are believed to provide valuable inputs for the program, with respect to qualitative methods, routes, decisions or themes that emerge from the mapping of how visitors explore the zoo means an effort to understand how participation connects to the zoo and offer a possibility to improve the quality of visit in the zoo.

\section{Result and Discussion}

The need for a new wayfinding system initially emerged from the Ragunan management office that aims to facilitate visitors in navigating the zoo and inspire them to learn from the exhibitions. Through some discussions between the management and our team, we recommended a wayfinding and signage system as one of the key opportunities to create a sense of place and improve navigation within the zoo. During the process, it was agreed that while the existing wayfinding system is consistent in some aspects of its design, there are also some challenges such as incomplete wayfinding system and signage could be improved in their placement and design.

The wayfinding strategy is the overall organizational and functional system that will create an underlying logic for the sign program for the Ragunan Zoo. The new wayfinding system will be structured around major pedestrian, animal exhibitions, entrances and public facilities. The wayfinding strategy can be applied to each zone in the Ragunan Zoo and includes a list of which entrances, pedestrians, zones, animal collections and attractions will be included. The strategy will also include a logic for directing users within the zoo and a dividing the zoo into four zones following the main entrances. Our team come up with the strategy to guide the sign types, content, placement and quantity by adding simple color-coded system to indicate zones and locations and enhancing identity conveyed in signage. It is our aim to create a comprehensive, and distinct wayfinding system as well as unique and simple signage design that overcomes physical and perceptual obstacles to help visitors exploring the Ragunan Zoo and celebrate what the zoo should offer.

During our surveys, we found that there are basically three target users:

a. Infrequent / Common Explorers

Common Explorers of Ragunan Zoo are basically visitors who come to the zoo for recreation and education, mostly local tourists. They usually come in small or big groups, such as families and friends. Common Explorers get around the zoo by walking, driving or by public transportation. They will use the zoo's wayfinding 
system to explore areas and familiarize themselves with the zoo areas during their visits, starting from the entrance or the parking area. Common Explorers also includes groups of school children who usually visit the zoo during school days, groups of relatives who celebrate an event, or groups of company's employees who have company's gathering.

b. Frequent / Regular Explorer

Regular Explorer likely to visit the zoo for a certain kind of activities mostly related to sports. They walk, cycle, jog, drive, or use public transportation to the parking space and then walk, jog or cycle in the zoo. They come to the zoo on a regular basis and possess a reasonable familiarity with its layout. Some Regular Explorer are also related to animal or plant observations

They are potentially first-time visitors and possess no familiarity with the zoo. Although the majority want to have leisure time, variety of visitors means that they have different purposes and motivations. Not to mention there is also variety in age, economic, cultural and educational backgrounds. From the observation, most visitors are low- to middle- class family since the entrance fee is relatively low comparing to other recreational areas in Jakarta. Family seems to spend more time at exhibits that are participatory and allowing children to touch, or involving physical activities such as moving and walking. Family also spend more time at the exhibits that involves interaction between visitors and the exhibits or between animals and zookeepers. Tigers, giraffes, and elephants are favorite animals for children and families try to locate where those animals are since the beginning of their visit.

The primary function of signs is as a mediator between the space and the user by descriptively or representing the unknown environment. Although wayfinding is typically a process dependent on perception, it involves the conscious development of spatial models. The process of wayfinding becomes a process of cognitive representations constructed as mental maps which guide our actions. The combination of perceptually guided action (what we see) with voluntary cognitive action (what we imagine) sets up the basis of wayfinding strategies. Signs become the main elements in this process that assist us in envisioning what spaces beyond our line of sight look like. In this way, the process of wayfinding is the process of cognitive mapping that helps people structure the visual or spatial information that we are supplied by our immediate surroundings, including signage. In structuring spaces, visitors need a sense of direction and some elements for recognition such as landmarks and landscape as we move to different places. The new signage system is designed to be a landmark for a particular area, in addition to existing landmark in the Ragunan Zoo such as the Statue of chimpanzee. Boundaries of regions, which are marked by colors, provide a spatial framework for positioning one self and create a mental representation that preserved survey knowledge of a familiar environment. 
Creating wayfinding systems in a comprehensive way can make the entire system simpler, more effective and less overwhelming to users. During the schematic design phase, the team conducted mapping of the whole zoo area and found that there was no clear classification of the animal exhibits. Unfortunately, it was not possible to move animals nor build new paths. The challenge came mainly from finding possible redirecting visitors to exhibits and creating a simple wayfinding system. In the end, since there were four main entrances following north-south-east-west directions, and the grouping of areas would follow the main entrances using colors as primary indicator (see Figure 1).

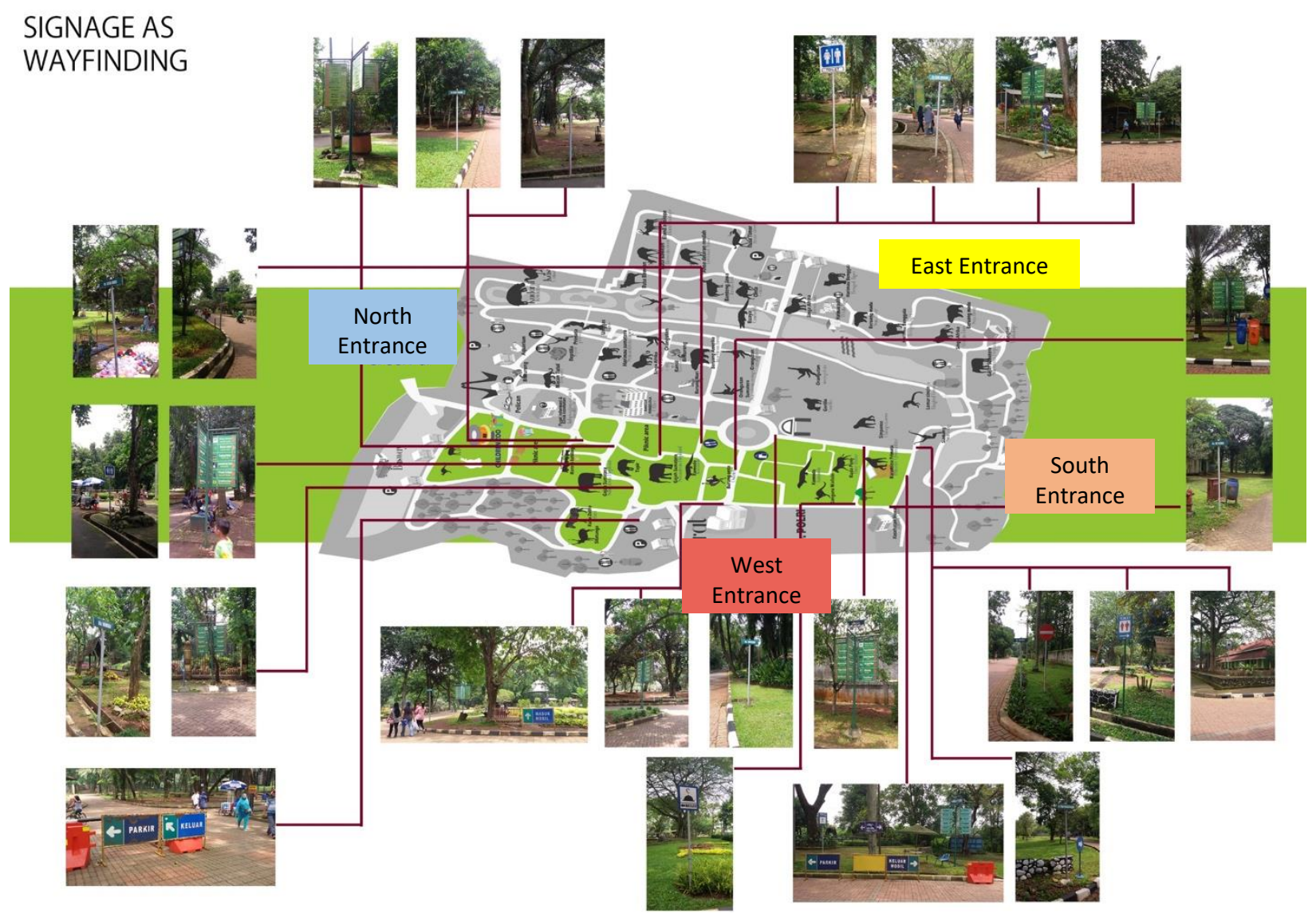

Fg. 1 Simulation of signage in the zoo environment Source: Author's collection

The design, layout and content of each sign should enable visitors of Ragunan zoo to meet their information needs and minimize the need to consult zoo staff and maximize operational efficiency. The design need to show an image of efficiency, consistency and leisure as well as Ragunan Zoo's corporate image. Good signing makes visitors have good impression and thus help the zoo gain customer satisfaction. Unfortunately, the early assessment showed that existing signage had no consistency in design, lettering, color, and what to show on the signage. The height of those signage did not accommodate the height of children and the font size was relatively small for visitors standing more than one meter from the signage (see Figure 2). 

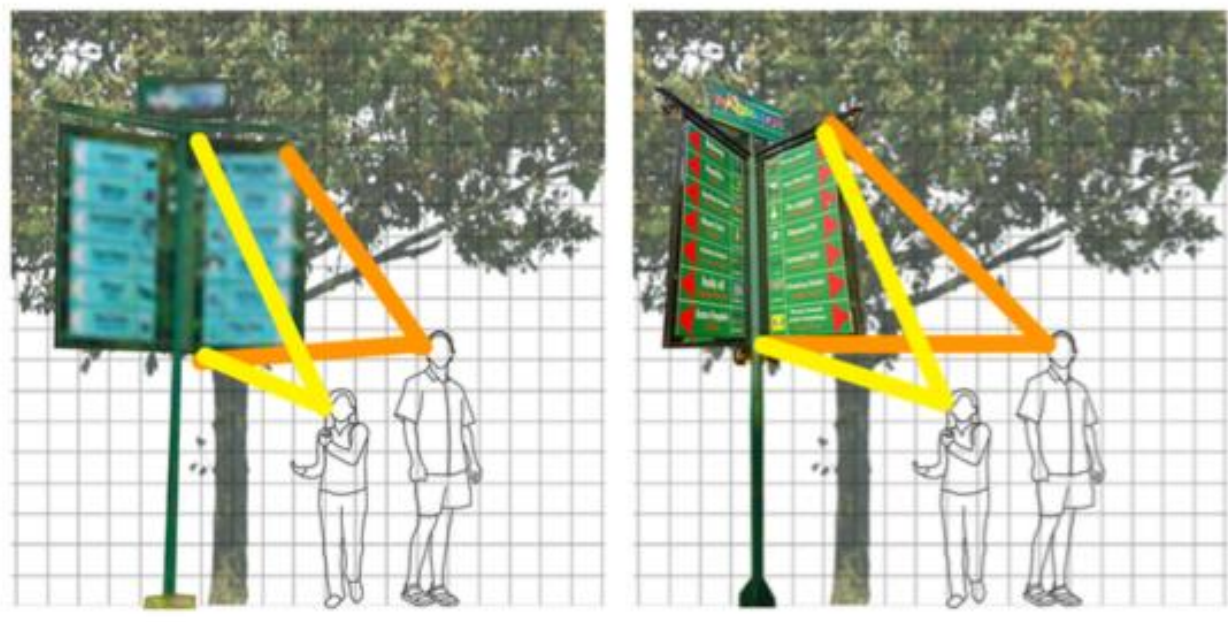

Fg. 2 Evaluation of existing signage in the zoo Source: Author's collection

To guide visitors step by step through the wayfinding process, one needs a wellthought-out system that includes signage and additional sources of information (from physical and digital platforms). A system should meet all the requirements involved by developing wayfinding solutions that go far beyond the design of signs. Psychology, ergonomics, safety factors, architecture, top-quality graphics, digital strategies and GPS systems all play crucial roles in the creation of a wayfinding concept. There is actually the Ragunan zoo-apps that may help to navigate using GPS information from digital platforms. However, users of this zoo-apps will still rely on the wayfinding system to confirm the information from the zoo-apps. In line with what Norberg-Schulz has mentioned on spatial relations earlier, even though visitors already have a map from the zoo-apps, to function well the digital maps, require visitors to have spatial relations to the real condition in the zoo and unify them in a space concept. It means that in orienting one self, signage and landmark are crucial in helping visitor to make spatial relations with the environment.

There are some phases in designing wayfinding and signage system, namely programming, design and implementation. In programming, all the exhibitions and facilities that will appear on signage are plotted on a map which connected to the entrances, and some important decision points to reach each destination. It is important to define different kind of zones in relation to the entrances so that it is easy for visitors to go back to their first entrance. During this phase, a strategy for working with the signage location is developed. In design phase, there are three different kind of signage, maps, location of destinations, and detail information on a particular collection. Design concepts will be developed for each sign type during the initial design phase including considering color, graphics, typography, form, and size. Final design includes details of materials and construction. During implementation phase, detailed drawings and documents will be prepared for a procurement process. After that, supervision on the fabrication and installation is also important to confirm that all signs are built with a consistent design. The team then develop a design manual to document the process and to suggest maintenance and future development.

We set out some aspects for the project to help guide development of the wayfinding strategy and signage design. Those aspects are related systematical information and 
visual aspects so that people have more time and interest to explore the zoo collection. Those aspects are:

a. Convey an identity for the zoo

Some requirements of a good wayfinding and signage systems in the zoo are based on the expectations of the user as well as identity of the zoo. Therefore, those systems should be comprehensive, clear, consistent and conspicuous. A comprehensive signage offers information that people need and usually has a hierarchical information to create the simplest structure for understanding and visualizing complexity. A clear signage system means that the signage should be userfriendly and easy to understand. The texts should be easy to be read and have a high contrast in relation to the background. A consistent signage system means that the position of signage meets visitors' expectation, has a consistent terminology, as well as consistent branding elements (e.g. company logo). A conspicuous signage system means that the signage is easy to be seen for example colors used should be based on their quality of visibility so that the signage is easy to be seen in "noisy" environments. Moreover, a conspicuous signage system has attractive elements of the environment as well as identity of the zoo as recreational, educational and conservational destinations.

b. Encourage adventure and exploration

Wayfinding in the zoo includes not only how people connect themselves to the environment but also both cognitive maps and architectural features. Signage in the zoo should inform and direct pedestrians to the nearest destinations including public facilities. In relation to the location, signage will be placed in strategic areas on the sidewalk, either on one side or back-to-back. Signage are to be mounted in such a way that it is perpendicular on the flow within the sight line. Pedestrian directional will be placed mostly on primary corridors within the zoo, especially at the approach to an intersection. Hopefully, the system of wayfinding will encourage exploration.

c. Welcome visitors while creating a sense of safety and comfort

Signage and way finding are most usually expressed in united sign programs that informationally and visually interweave a site and a collection of related sites (Calori \& Vanden-Eynden, 2015). Well-designed signage programs help to visually unify a site, while signage can also function to establish a unique identity and sense of place. Moreover, wayfinding and signage programs can also communicate other kinds of information, such as warning and operational information. Signage has a variety of forms, presenting various methods of regulating the location, size, and other features associated with on premise signs. Such sign codes are often developed at the local level and may rely upon aesthetic preferences. Visitors want concrete information from the display, but the signage or labels often focus on more abstract concepts. Because visitors spend longer periods viewing exhibits at the beginning of their visit (Taylor, 1986), signage should work very well at the beginning of the visit so that visitors grasp the information they need.

d. Integrate universal design principles

Since the aspect of visual representation is critical for wayfinding, the chosen representation codes such as maps and pictograms should engage a minimum degree of learning. There is a hierarchical mapping through the range of information given in big signage found near the main entrances and smaller signage found at some important crossings and signage found in front of animal exhibits as a way of familiarizing users with spaces. The aim of those hierarchical mapping is to simplify decision-making when users navigate and the process of "diagramming" routes and 
destinations encourage users to locate main destination zones and then to more specific spaces.

In integrating the signage system into the zoo environment, there are some important considerations. First, it is important to agree on clear zone boundaries, so that only destinations that fall within those boundaries are included, and are branded appropriately as belonging to that specific zone. Main entrances as well as primary and secondary corridors should also be identified. Second, a survey of the existing signage in the zoo will help to understand what signage functions well and not so well, which will be helpful in the implementation phases. A geospatial database should identify all sign locations and photographs to determine sign condition. Third, developing a zoo identity with stakeholders that will be leveraged during the signage design phase.

For signage, we decided to use solid primary colors to enhance visibility and emphasize typography and symbols using contrast. Since the issue of color contrast is important in considering the performance criteria of the signage, we put this consideration in the signage design (see Figure 3). Hopefully, the application is also useful especially for users whose sensory abilities have been reduced.
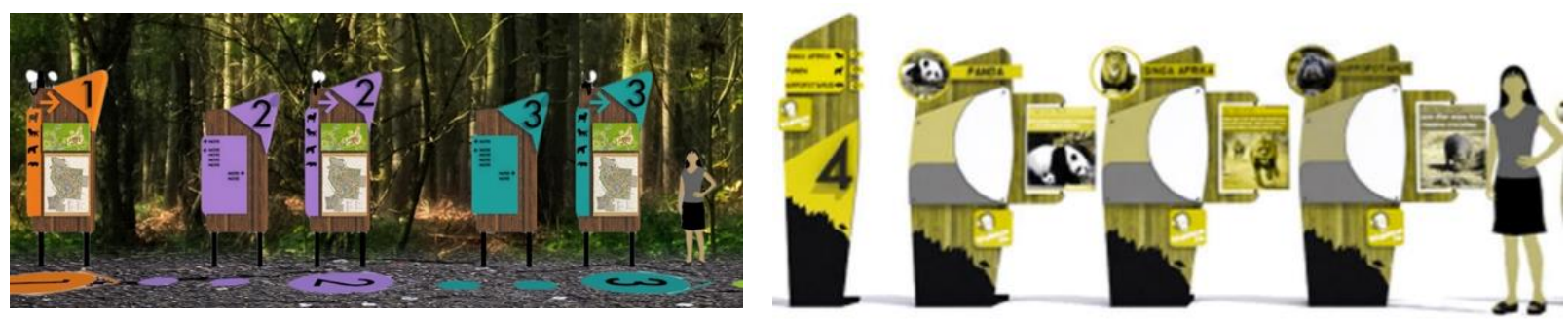

Fg. 3 (a) Early simulation of color and words in the zoo environment (b) simulation of contrasts Source: Author's collection

In the process of designing signage for the Ragunan Zoo, some concerns to be addressed are the visibility and the readability of the sign, the clarity information and wayfinding, the character and images the sign are portraying, the consistency of signage system and the cost and maintenance. These concerns can be played out in a schematic design phase, whose goal is to create specific design concepts and to create desirable visual qualities. The schematic design is like an architectural blueprint, offering an overview of all the important components of the program.

Some principles of wayfinding that we apply to the Ragunan Zoo is by trying to create identity to each important zone. Since visitors come from different main entrances, we give each entrance its own color: the north entrance is blue (following the bus color), the east entrance is yellow (the sunrise color), the west entrance is red (the sunset color) and the south entrance is orange (requested by the zoo management). To simplify the navigation, there are both symbols of animals and letters in each signage. The use of the map is necessary and we put the maps near the main entrances with some pictograms of animals (Figure 4). There are different visual characters of each zone that indicate different zone and animal collections in the area but there is a consistency in using letter, size, symbol and color. 

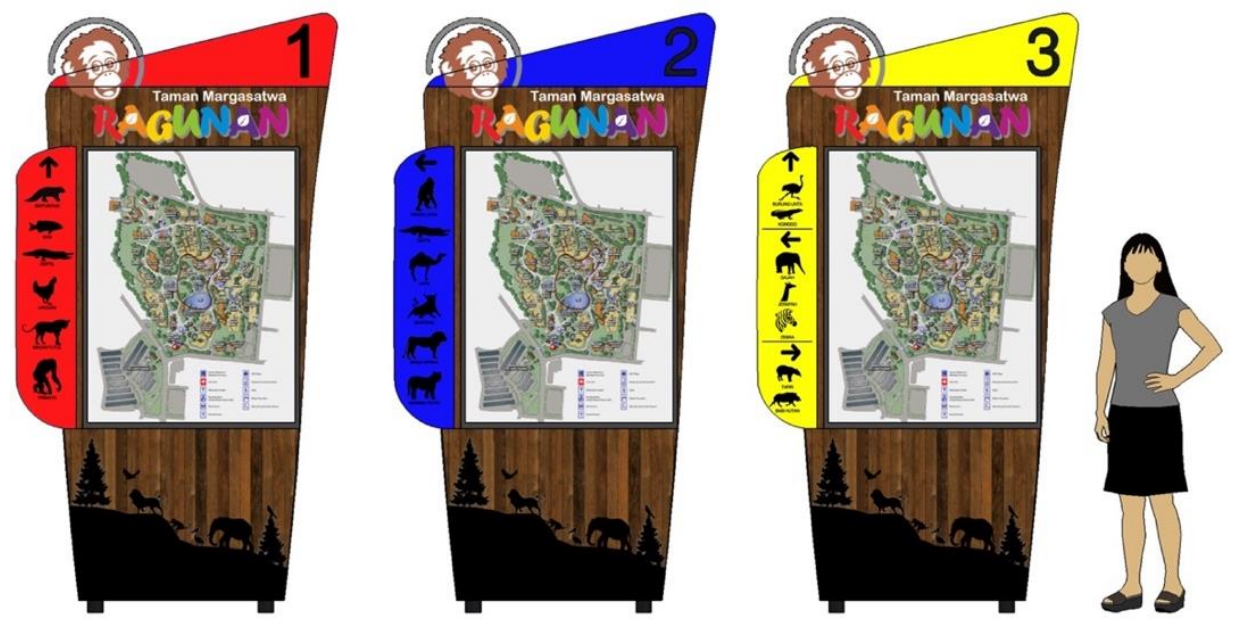

Fg. 4 Proposed signage for main entrances.

Source: Author's collection

Since visitors want concrete information from the display, the new signage works simultaneously to emphasize important information through letters, symbols, colors, and pictograms. Because visitors spend longer periods viewing exhibits at the beginning of their visit, it is important for signage to function very well at the beginning of the visit or near the entrance.
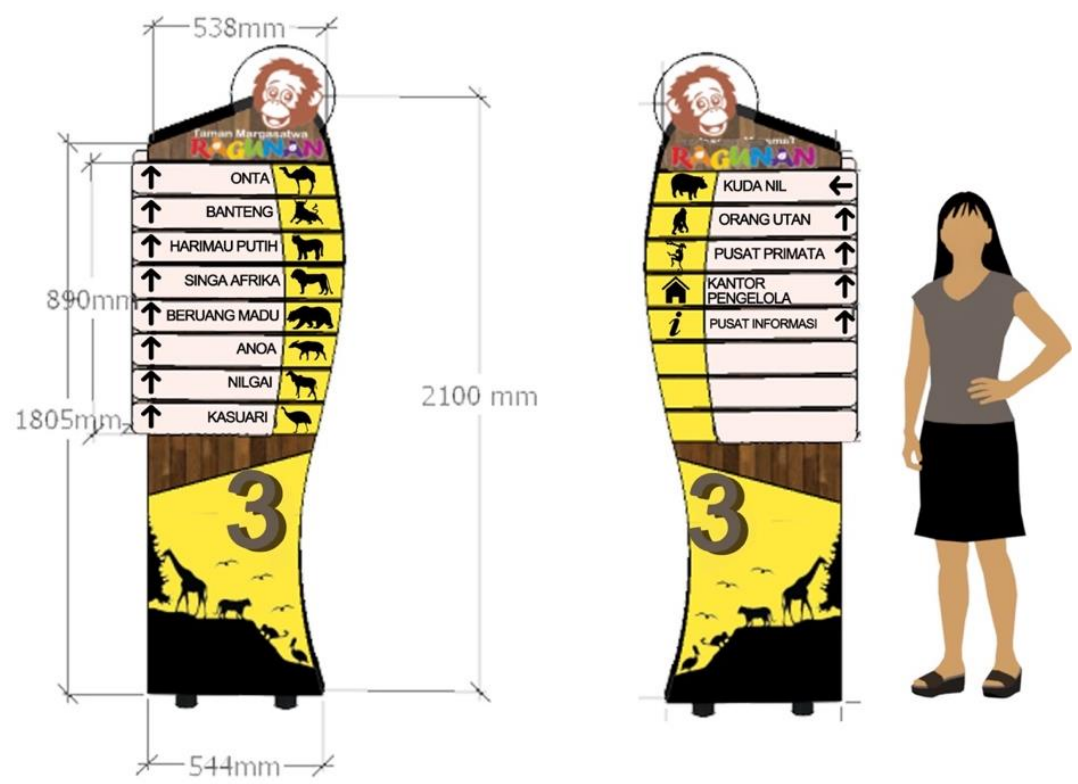

Fg. 5 Proposed signage for important crossings.

Source: Author's collection

We not only locate signs at decision point, but also establish clear sight line to aid navigation and provide a universal visual language. We carefully design details for the signage to reach the broadest audience possible. For showing the location of the exhibits, the round form is chosen to show dynamic and playfulness of the design as well as giving greater contrast when viewed with other street signings (Figure 5). Ideally, the round forms should be placed on a white background but since the Ragunan 
Zoo has green and various colors, the lower part of the signage has black silhouette to attract attention to the information of the upper part. The use of primary colors for the zoo is a way to give clarity and consistency of wayfinding system.

There are some rules of signage that follows colors, animal exhibits and facilities. Arrows, lettering and pictograms are separated so that the diagram show clarity and consistency. Visitors should be given immediate directions to any exhibits at junctions. Double indicators, colors and numbers, are applied in a consistent manner to ensure visitors know where to look for information. Pictograms serve as recognizable pictorial representations which can make signs more easily comprehensible. In this way, the design presents united sign programs that informationally and visually interweave the site, the collections and the identity of the place. The unity of forms, which presents colors, pictograms and letters to regulate locations, is achieved through aesthetic considerations that gives concrete information rather than abstract concepts. Although it may not always be possible to position signs ideally, each location will have to be considered individually on its own merits. The dimension of the map panel is 240 centimeters and 100 centimeters while the height of the signage is 210 centimeters and 54 centimeters. Those dimensions are related to the effective sight of visitors.

The existing signage system in Ragunan Zoo experiences issues with fading, as well as sign disorder. As new signs are added without removing redundant signs, in consideration of the high costs associated with new signage system implementation, the zoo management decides to keep the existing signage system. To prevent confusion, there will be a transitional period in which both systems are present and some analysis on sign placement is conducted. To prevent any overlapping locations that could cause confusion, the new signage will be placed in strategic locations. Moreover, the new signage will make use of existing sign posts and structures wherever practical.

\section{Conclusion}

The existing wayfinding and signage system in the Ragunan Zoo does not effectively give clear information to visitors. This condition creates confusion for visitors in exploring the zoo and makes visitors have less time to enjoy the exhibits and even reduce their time to reach education and conservation goals. After mapping visitors' movement pattern, facilities and the location of animal collections, we analyze the needs of signage and proposed a more comprehensive system by using some basic principles of wayfinding and signage design. People are capable of various methods of wayfinding depending not only on the information available to them but also considerations of efficiency and aesthetics. By applying basic principles of wayfinding such as structuring space and good signage designs such as visual representation, hopefully visitors can connect themselves to the environment through cognitive maps and architectural feature. The new signage design considered not only users' needs but also applied rules of signage, such as the use of colors, pictograms, arrows, and lettering that engage a minimum degree of learning. The new signage system uses hierarchical mapping through various range of information given in signage placed in different locations to simplify decision-making when users navigate in the zoo. Some important aspects of wayfinding and signage systems that our team are found during the project are related to the idea that signage should convey the identity for the zoo, encourage adventure and exploration, welcome visitors while creating a sense of safety and comfort, and integrate universal design principles. By applying some principles of wayfinding and good signage designs for the Ragunan Zoo, hopefully visitors will have more time to enjoy their visit and involve in education and conservation activities. 


\section{Acknowledgements}

We would like to thank our team members Nevine Rafa, Dini Puti, Amalia Nurul Rizky, Ayu Ginarani, Astari, Annisa Putri Lestari, Anneli Xenia, and Anisa Wisnu Putri for providing data from literature and conducting field research, as well as contributing in the design process. This program is supported by Universitas Indonesia through its Pengabdian Masyarakat scheme. Many thanks for our partners in the Ragunan Zoo, Mrs. Susi Sondang and Mr. Ketut Arsana, for sharing materials and good discussions.

\section{References}

Arthur, P. and Passini, R. (1992). Wayfinding-People, Signs, and Architecture. New York: McGraw-Hill.

Benton, D. P. (1979). Intergenerational Interaction in Museums. Ed.D. diss., Columbia University Teacher's College.

Calori, C., \& Vanden-Eynden, D. (2015). Signage and Wayfinding Design: A Complete Guide to Creating Environmental Graphic Design Systems. New Jersey: John Wiley \& Sons.

Coates, K. E. A. (2014). Introduction to Information Design. London: Laurence King Publishing. Retrieved from http://ebookcentral.proquest.com/lib/indonesiauebooks/detail.action?docID=1876178

Cornell, E. H. , and C. D. Heth, (2000). Route Learning and Wayfinding. In Cognitive Maps: Past, Present, and Future, ed. R Kitchin and S. Freundschuch, 66-81. London: Routledge.

Cornell, E., Sorenson, A., \& Mio, T. (2003). Human Sense of Direction and Wayfinding. Annals of the Association of American Geographers, 93(2), 399-425. Retrieved from http://www.jstor.org/stable/1515565

Correa de Jesus, S. (1994). Environmental Communication: Design Planning for Wayfinding, Design Issues, Vol. 10, No. 3, 32-51.

Csikszentmihalyi, M. (1990). Flow The Psychology of Optimal Experience. New York: Harper Perennial. Also see Richard Buchanan's review of Flow in Design Issues, 8 no. 1 (Fall 1991): 80-1.

Gibson, D. (2009). Wayfinding Handbook. New York: Princeton Architectural Press.

Golledge, R. G. (1995). Primitives of spatial knowledge. In Cognitive aspects of humancomputer interaction for geo? graphic information systems, ed. T. Nyerges, D. Mark, R. Laorini, M. Egenhofer, 29-44. Dordrecht: Kluwer Academic.

Hart, R.A., GT. Moore. (1973). The development of spatial cognition: A Review. In Image and Environment. ed. R. M. Downs and D. Stea. 246-88. Chicago: Aldine 
Kling, B. K. T. (2013). Signage - Spatial Orientation. München: DETAIL. Retrieved from http://ebookcentral.proquest.com/lib/indonesiauebooks/detail.action?docID=1383647

Kozlowski, L. T, and K. J. Bryant. (1977). Sense of direction, spatial orientation, and cognitive maps. Joumal of Experimental Psychology: Human Perception and Performance 3:5.

Kropf, M. B. (1989). The Family Museum Experience: A Review of the Literature. Journal of Museum Education 14(2), 5-8.

Lars, L. L. (1991). Zoo Interpretation and Exhibit Design: Two Sides of the Same Coin. The Journal of Museum Education 16(2), 4-6. Retrieved from http://www.jstor.org/stable/40478892. Accessed: 26-09-2017.

Meuserdan, P \& DPogade, D. (2010). Construction and Design Manual Wayfinding and Signage. Singapore: Page One Publishing.

Minkler, M. and Wallerstein, N. (Eds.). (2003) Community-based Participatory Research for health. San Francisco, CA: Jossey-Bass.

Norberg-Schulz, C. (1971). Existence, Space, and Architecture. New York and Washington: Preager Publishing.

Poulin, R. (2012). Graphic Design and Architecture, A 20th Century History. Osceola: Rockport Publishers. Retrieved from http://ebookcentral.proquest.com/lib/indonesiauebooks/detail.action?docID=3399636

Taylor, S. (1986). Understanding Process of Informal Education: Naturalistic Study of Visitors to a Public Aquarium. Ph.D. diss., University of California, Berkeley.

The Jakarta Post, (2017). Ragunan Zoo holidaymakers surprised by Jokowi. June 30, 2017. Retrieved November 2017. https://www.pressreader.com/indonesia/thejakarta-post/20170630/281651075122403. See also in the Jakarta Post Ragunan Zoo, Ancol gear up for annual visitor influx. July 5, 2017. Retrieved 19 December 2017. http://www.thejakartapost.com/news/2016/07/05/ragunan-zoo-ancol-gearup-for-annual-visitor-influx.html

Vit, A. P. B. G. G. (2009). Graphic Design, Referenced. Osceola: Rockport Publishers.

Zwaga, H. B. T. H. H. (1998). Visual Information for Everyday Use. London: CRC Press. 